\title{
Syntheses and Biological Activities of Tetramic Acid and Tetronic Acid Derivatives
}

\author{
Akira IbI, Eiji Taniguchi and Kazuyuki MaEKaWA* \\ Lab. of Pesticide Chemistry, Faculty of Agriculture, Kyushu University Fukuoka \\ *Dept. of Engineering, Kyushu Kyoritsu University, Kita-Kyushu
}

Received November 2, 1978

\begin{abstract}
Fifteen derivatives of 5-substituted tetronic acid (VII) and five derivatives of 3-acetyl-5substituted phenyltetramic acid (III) were prepared and their biological activities were investigated. Among the compounds tested, 3-carboethoxy derivatives of tetronic acid showed a remarkable stimulating effect on the growth of rice roots, while the compounds which were removed the carboethoxy group from their 3-position displayed a strong inhibitory effect on the growth of rice roots and stalks. The fungicidal activity against Asp. niger and the effects on pupation and enzrgence of the housefy were also investigated as to the compounds synthesized.
\end{abstract}

Derivatives of tetramic acid are known as secondary metabolites of microorganisms. ${ }^{11}$ Some of them display biological activities such as herbicidal, plant regulatory, ${ }^{2)}$ antitumor, ${ }^{3 !}$ and antibiotic activities. ${ }^{4}$

The derivatives of tetronic acid are mainly produced by fungi (e.g., Penicillium charlesci, $P$. fellutanum etc.) and lichens (e.g., Sticta coronta, etc.). Some of them also have biological activities. ${ }^{\text {s }}$

The present experiment dealt with syntheses of 5-aryltetramic acid (III) and 5-aryltetronic acid derivatives (VII) from substituted benzaldehyde. In addition, a condensation reaction of 5-aryltetronic acid with substituted benzaldehyde is described. Finally, a series of these compounds was evaluated for their biological activities.

\section{CHEMISTRY}

Substituted benzaldehydes were converted with good yields to aminonitril derivatives by condensing them with sodium cyanide in the presence of ammonium chloride. The nitrils were hydrolyzed to $\alpha$-phenylglycine hydrochloride derivatives. After esterification of the carboxyl groups, they (I) were converted into acetoacetyl derivatives (II) with diketene according to Lacey's procedure, then cyclized to 3-acetyl-5-aryltetramic acid derivatives (II) with alcoholic sodium ethoxide. ${ }^{8)}$ The synthetic route is shown in Scheme 1. The compounds thus obtained are listed in Table I.

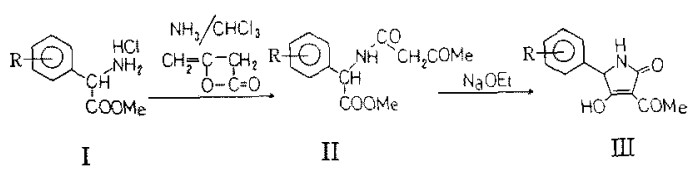

SCHEmE 1. Synthesis of Tetramic Acid Derivatives.

Diethyl $O$-acetylmandelylmalonate (V) was obtained from $O$-acetylmandelyl chloride (IV) and sodium diethylmalonate. ${ }^{11)}$ The following ring-closure of this compound was performed by acidifying it with diluted hydrochloric acid. 5-Aryltetronic acid (VII) was obtained by hydrolysis of the ester group followed by decarboxylation of the compound (VI). Substituted 5 -aryltetronic acid derivatives were prepared usually by this method (Scheme 2).

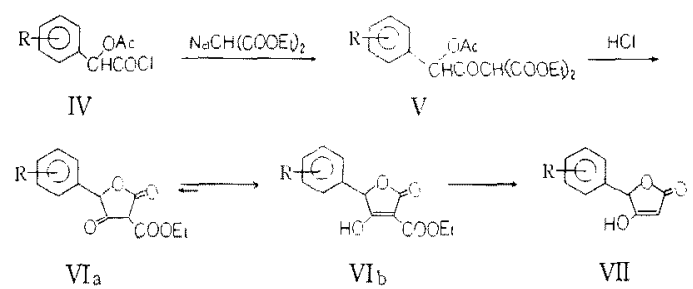

SCHEME 2. Synthesis of 5-Aryltetronic Acid Derivatives.

Then, the condensation of 5-aryltetronic acid (VII) with benzaldehyde derivatives in the presence of piperidine and benzoic acid was conducted. By the condensation of 5-aryltetronic acid with benzaldehyde, 3(2-hydroxybenzyl)-5-phenyltetronic acid (VIII) (trace) and 3-benzylidene-4-keto-5-phenylbutanolide(IX) $(74 \%)$ were obtained. In the case of $p$-tolualdyde, $3-(p-$ 


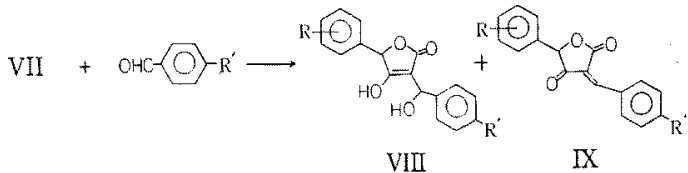

SCHEME 3. Condensation of 5-Phenyltetronic Acid with Aromatic Aldehyde.

methylbenzylidene)-4-keto-5-phenyl-4-butanolide (IX, $\mathrm{R}^{\prime}=\mathrm{CH}_{3}$ ) was obtained, as shown in Scheme 3 . The tetronic acid derivatives thus obtained are summarized in Table II.

\section{EXPERIMENTAL}

Preparation of tetramic acid derivatives

a) $N$-Acetoacetyl-a-phenylglycine methylester
$R=H$ ). Into a chloroform solution containing $12 \mathrm{~g}$ of $\alpha$-phenylglycine methylester ${ }^{7)}(\mathbf{I}, \mathbf{R}=\mathbf{H})$ dry ammonia gas was passed with stirring. After $3 \mathrm{hr}$ the reaction mixture was filtered to remove ammonium chloride. The filtrate was evaporated to a syrup and then mixed with $5 \mathrm{ml}$ of diketene. After $2 \mathrm{hr}$ chloroform and excess diketene were evaporated off to leave a crystalline material, which was crystallized from ethyl acetate. Yield $10.5 \mathrm{~g}(58 \%)$, mp $83 \sim 84^{\circ} \mathrm{C}$.

Other $N$-acetoacetyl $\alpha$-substituted phenylglycine methylesters were synthesized by the same method.

b) 3-Acetyl-5-phenyltetramic acid (III, $R=H$ ). $\mathrm{N}$ Acetoacetyl $\alpha$-phenylglycine methylester (III, $\mathrm{R}=\mathbf{H}$ ) $(0.05 \mathrm{~mol}, 12.5 \mathrm{~g})$ in dry benzene was added dropwise to a solution of sodium methoxide $(0.05 \mathrm{~mol}$ of sodium in methanol and benzene) and the solution was heated under reflux for $3 \mathrm{hr}$. After cooling, the reaction mix(II, ture was extracted with water. The aqueous solution

Table I. Analytical Data of 3-Acetyl-5-aryltetramic Acid Derivatives

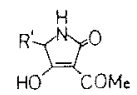

\begin{tabular}{|c|c|c|c|c|c|c|}
\hline No. & $\mathrm{R}^{\prime}$ & $\operatorname{mp}\left({ }^{\circ} \mathrm{C}\right)$ & Yield* $(\%)$ & Recryst. solvent & Mol. formula $^{a}$ & Ref. \\
\hline 1 & (a) & $125 \sim 6$ & 70 & AcOEt & $\mathrm{C}_{12} \mathrm{H}_{11} \mathrm{O}_{3} \mathrm{~N}$ & 13 \\
\hline 2 & $<0$ & 147 & 80 & AcOEt & $\mathrm{C}_{13} \mathrm{H}_{11} \mathrm{O}_{5} \mathrm{~N}$ & \\
\hline 3 & ${ }^{M e 0}$ Øつ & $148 \sim 9$ & 65 & AcOEt & $\mathrm{C}_{13} \mathrm{H}_{13} \mathrm{O}_{4} \mathrm{~N}$ & \\
\hline 4 & Me & 136 & 39 & AcOEt, Ether & $\mathrm{C}_{18} \mathrm{H}_{13} \mathrm{O}_{3} \mathrm{~N}$ & \\
\hline 5 & $\mathrm{Cl}$ & $164 \sim 6$ & 45 & AcOEt, Ether & $\mathrm{C}_{12} \mathrm{H}_{10} \mathrm{O}_{3} \mathrm{NCl}$ & \\
\hline
\end{tabular}

* Yield is overall for the diketene addition and cyclization.

a Analyses for $\mathrm{C}, \mathrm{H}$, and $\mathrm{N}$, within $\pm 0.4 \%$ of calculated values except where noted.

Table IIa. Analytical Data of 3-Carboethoxy-5-ARyltetronic Acid Derivatives

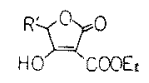

\begin{tabular}{|c|c|c|c|c|c|}
\hline No. & $\mathbf{R}^{\prime}$ & Yield* $(\%)$ & $\mathrm{mp}\left({ }^{\circ} \mathrm{C}\right)$ & Recryst. solvent & Mol. formula ${ }^{b}$ \\
\hline 6 & (a) & 32 & 134 & $\mathrm{MeOH}, \mathrm{H}_{2} \mathrm{O}$ & $\mathrm{C}_{13} \mathrm{H}_{12} \mathrm{O}_{5}$ \\
\hline 7 & 81 & 23 & 140 & $\mathrm{MeOH}, \mathrm{H}_{2} \mathrm{O}$ & $\mathrm{C}_{14} \mathrm{H}_{12} \mathrm{O}_{7}$ \\
\hline 8 & $\mathrm{MeO}_{\mathrm{T}}$ & 16 & $145 \sim 6$ & AcOEt, $\mathrm{MeOH}$ & $\mathrm{C}_{14} \mathrm{H}_{14} \mathrm{O}_{6}$ \\
\hline 9 & $\mathrm{Oll}^{\text {one }}$ & 10 & 152 & AcOEt, $\mathrm{MeOH}$ & $\mathrm{C}_{14} \mathrm{H}_{14} \mathrm{O}_{8}$ \\
\hline 10 & & 25 & 143 & AcOEt, $\mathrm{MeOH}$ & $\mathrm{C}_{14} \mathrm{H}_{14} \mathrm{O}_{5}$ \\
\hline 11 & $\mathrm{Ol}^{\mathrm{Cl}}$ & 22 & 169 & AcOEt, $\mathrm{MeOH}$ & $\mathrm{C}_{13} \mathrm{H}_{11} \mathrm{O}_{8} \mathrm{Cl}$ \\
\hline 12 & & trace & 142 & AcOEt, $\mathrm{MeOH}$ & $\mathrm{C}_{15} \mathrm{H}_{14} \mathrm{O}_{8}$ \\
\hline
\end{tabular}

* Yield is overall from mandelic acids.

b Analyses for $\mathrm{C}$ and $\mathrm{H}$, within $\pm 0.4 \%$ of calculated values except where noted. 
Table IIb. Analytical Data of 5-Aryltetronic Acid Derivatives

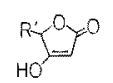

\begin{tabular}{|c|c|c|c|c|c|}
\hline No. & $\mathbf{R}^{\prime}$ & Yield $(\%)$ & $\mathrm{mp}\left({ }^{\circ} \mathrm{C}\right)$ & Recryst. solvent & Mol. formula ${ }^{b}$ \\
\hline 13 & (Q) & 73 & 120 & $\mathrm{M} \rightleftharpoons \mathrm{OH}$ & $\mathrm{C}_{10} \mathrm{H}_{8} \mathrm{O}$ \\
\hline 14 & 跑 & 62 & 89 & $\mathrm{MeOH}$ & $\mathrm{C}_{11} \mathrm{H}_{8} \mathrm{O}_{5}$ \\
\hline 15 & MeO & 89 & $181 \sim 4$ & $\mathrm{M} \geqslant \mathrm{OH}$ & $\mathrm{C}_{11} \mathrm{H}_{10} \mathrm{O}_{4}$ \\
\hline 16 & $\widehat{O}^{\text {OMe }}$ & 69 & 134 & $\mathrm{CHCl}_{3}$ & $\mathrm{C}_{11} \mathrm{H}_{10} \mathrm{O}_{4}$ \\
\hline 17 & Me & 75 & 150 & AcOEt, $\mathrm{MeOH}$ & $\mathrm{C}_{11} \mathrm{H}_{10} \mathrm{O}_{5}$ \\
\hline 18 & $\hat{\mathrm{O}}^{\mathrm{Cl}}$ & 61 & 157 & AcOEt, $\mathrm{MeOH}$ & $\mathrm{C}_{10} \mathrm{H}_{7} \mathrm{O}_{3} \mathrm{Cl}$ \\
\hline
\end{tabular}

Table IIc. Analytical Data of 3-(2-Hydroxybenzyl)-5-Phenyltetronic ACid and 3-SUBSTITUTED BENZYLIDENE-4-KETO-5-PHENYL-4-BUTANOLIDES

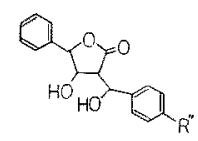

19

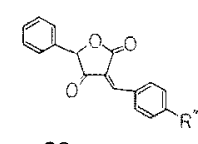

20 ,

\begin{tabular}{clcclc}
\hline No. & $\mathrm{R}^{\prime \prime}$ & $\mathrm{mp}\left({ }^{\circ} \mathrm{C}\right)$ & Yield & Recryst. solvent & Mol. formula $^{b}$ \\
\hline 19 & $\mathrm{H}$ & $222 \sim 4$ & trace & ethylacetate & $\mathrm{C}_{17} \mathrm{H}_{14} \mathrm{O}_{4}$ \\
20 & $\mathrm{H}$ & $137 \sim 8$ & 74 & ethylacetate & $\mathrm{C}_{17} \mathrm{H}_{12} \mathrm{O}_{3}$ \\
21 & $\mathrm{CH}_{3}$ & 141 & 66 & ethylacetate & $\mathrm{C}_{18} \mathrm{H}_{15} \mathrm{O}_{3}$ \\
\hline
\end{tabular}

was carefully acidified with concentrated sulfuric acid and repeatedly extracted with ether. After washing and drying, the ether was evaporated to give an oily product, which was crystallized from ethyl acetate and petroleum ether, yield $7.4 \mathrm{~g}(68 \%)$, mp $125 \sim 126^{\circ} \mathrm{C}$.

\section{Preparation of tetronic acid derivatives}

a) O-Acetyl-3,4-methylenedioxymandelic acid. This compound was prepared from $5.6 \mathrm{~g}$ of dry 3,4-methylenedioxymandelic acid and $6.4 \mathrm{ml}$ of acetyl chloride with stirring for $3 \mathrm{hr}$. After removal of the solvent and excess acetyl chloride and recrystallization from benzene and ethyl acetate, $O$-acetyl-3,4-methylenedioxymandelic acid was obtained as colorless crystals. Yield 3.6 g (53\%), mp 107 108 ${ }^{\circ} \mathrm{C}$. Found: C, 55.31; $\mathrm{H}, 4.23$. Calcd. for $\mathrm{C}_{11} \mathrm{H}_{10} \mathrm{O}_{8}: \mathrm{C}, 55.46 ; \mathrm{H}, 4.23 \%$.

Other $O$-acetyl-substituted mandelic acids were synthesized by a similar method.

b) O-Acetyl-3,4-methylenedioxymandelyl chloride (IV, $R=3,4$-methylenedioxy). A solution of $4 \mathrm{~g}$ of acetyl-3,4-methylenedioxymandelic acid in dry benzene was refluxed for $2 \mathrm{hr}$ with $5 \mathrm{ml}$ of thionyl chloride. The product was purified by vacuum distillation. bp $119 \sim 120^{\circ} \mathrm{C} / 0.06 \mathrm{mmHg}$. Yield, $3.3 \mathrm{~g}(81 \%)$.

Other substituted mandelyl chlorides were synthe- sized in the same way.

c) 3-Carboethoxy-5-(3,4-methylenedioxyphenyl)-tetronic acid (VI, $R=$ methylenedioxy).

(Method A): Freshly prepared ethyl malonate $(27 \mathrm{~g})$ and sodium $(3.9 \mathrm{~g})$ were mixed in dry benzene $(100 \mathrm{ml})$ and the mixture was refluxed with stirring for about $20 \mathrm{hr}$. To this solution, $13.5 \mathrm{~g}$ of $O$-acetyl-3,4methylenedioxymandelyl chloride (IV, $\mathrm{R}=3$,4-methylenedioxy) in $15 \mathrm{ml}$ of dry benzene was added dropwise with stirring. The stirring was further continued for $7 \mathrm{hr}$ to complete the reaction. Then, the reaction mixture was extracted with water. The aqueous extract (without further purification) was acidified with diluted hydrochloric acid to give the desired compound, which was crystallized from aqueous methanol, yield $7.7 \mathrm{~g}(53 \%)$, mp $140^{\circ} \mathrm{C}$.

Other 3-carboethoxy-5-aryltetronic acid derivatives were synthesized in the same fashion.

(Method B): To dry benzene containing $1.8 \mathrm{~g}$ of sodium hydride, $12 \mathrm{~g}$ of diethylmalonate in dry benzene was added. After stirring for $3 \mathrm{hr}$. at $80^{\circ} \mathrm{C}, 12 \mathrm{~g}$ of $o$-acetyl-3,4-methylenedioxymandelyl chloride in dry benzene was aded dropwise. ${ }^{12}$ The stirring was continued for $1 \mathrm{hr}$ at the same temperature. Then, the solution was extracted with water. The aqueous layer 
was acidified to give the precipitate of the aim. Yield, $3.7 \mathrm{~g}(28 \%)$. The yield by this method was generally lower than that by method $\mathrm{A}$.

\section{Decarboxylation of tetronic acid derivatives}

About $2.5 \mathrm{~g}$ of 3-carboethoxy-5-phenyltetronic acid were dissolved in $30 \mathrm{ml}$ of an aqueous conc. $\mathrm{KOH}$ solution and refluxed gently for $2 \mathrm{hr}$ to hydrolyse the ester groups. The alkaline reaction mixture was carefully acidified with hydrochloric acid with stirring. After completion of the evolution of $\mathrm{CO}_{2}, 5$-phenyltetronic acid (VII, $\mathrm{R}=\mathrm{H}$ ) was obtained as white crystals. The recrystallization was carried out from methanol. Yield $1.3 \mathrm{~g}(73 \%), \mathrm{mp} 120^{\circ} \mathrm{C}$.

Other 5-aryltetronic acids were prepared similarly.

\section{Condensation of tetronic acid derivatives with aromatic aldehyde}

a) 3-(2-Hydroxybenzyl)-5-phenyltetronic acid (VIII) and 3-benzylidene-4-keto-5-phenyl-4-butanolide (IX). Into a round-bottomed flask fitted with a water separator, $3.52 \mathrm{~g}$ of 5 -phenyltetronic acid (VII, $\mathrm{R}=\mathrm{H}$ ), $2.33 \mathrm{~g}$ of benzaldehyde, $0.2 \mathrm{ml}$ of piperidine, $0.1 \mathrm{~g}$ of benzoic acid and $100 \mathrm{ml}$ of benzene were poured successively. After the mixture was refluxed for $10 \mathrm{hr}$, it was washed with $1 \mathrm{~N} \mathrm{HCl}, 5 \% \mathrm{NaHCO}_{3}$, and then water. The organic layer was evaporated to give compounds (VIII and IX) which were purified through a silica gel column (solvent: AcOEt).

(VIII, $\mathrm{R}=\mathrm{H}, \mathrm{R}^{\prime}=\mathrm{H}$ ): $\quad$ Yield, trace, $\mathrm{mp} 222 \sim 224^{\circ} \mathrm{C}$ $(R f, 0.18$ TLC by AcOEt)

(IX, R=H, R'=H): Yield, $3.9 \mathrm{~g}(74 \%) . \quad \mathrm{mp} 137 \sim$ $138^{\circ} \mathrm{C}(R f, 0.23, \mathrm{TLC}$ by AcOEt)

b) 3-(p-methylbenzylidene)-4-keto-5-phenyl-4-butanolide ( $\mathrm{IX}, \mathrm{R}=\mathrm{H}, \mathrm{R}^{\prime}=\mathrm{CH}_{3}$ ). This compound was synthesized by the same method as that for the compound $\left(I X, R, R^{\prime}=H\right)$. It was purified through a silica gel column (solvent; hexane-benzene $=1: 9$ and benzene alone), and recrystallized from ethyl acetate. Yield, $66 \%$, mp $141^{\circ} \mathrm{C}$.

\section{BIOLOGICAL ACTIVITIES}

The derivatives of tetramic acid and tetronic acid were examined with regard to plant regulatory and phytotoxic effects on rice, radishes and barnyard grass, to the antifungal effect on Asp. niger, and to the toxic effect on houseflies.

\section{Phytotoxic and plant regulatory effects}

The chemicals to be tested were dissolved in $1 \sim 2 \mathrm{ml}$ of acetone or water. The solution was poured into a Petri-dish of $9 \mathrm{~cm}$ diameter, on the bottom of which a sheet of filter paper had been placed. After spontaneous evaporation of the solvent at room temperature, $10 \mathrm{ml}$ of distilled water was poured into the dish.
Into each Petri-dish, 20 seeds of radish, barnyard grass, or rice were placed and kept under continuous illumination at $25^{\circ} \mathrm{C}$. The activity was evaluated after 5 days by examining the rate of growth inhibition of both stems and roots.

The results are shown in Table IV. The derivatives of tetramic acid showed phytotoxic activity against radishes and rice at $250 \mathrm{ppm}$, but they did not display the activity at $100 \mathrm{ppm}$. In the case of derivatives of tetronic acid, the compounds carrying a carboethoxyl group at the 3-position had a remarkable stimulating effect on the growth of rice roots. On the other hand, the compounds lacking the carboethoxyl group had an inhibitory effect on the growth of rice roots and stalks.

The benzylidene derivatives displayed a stimulating effect on the growth of rice roots at a concentration of $100 \mathrm{ppm}$. However, each of the derivatives of tetramic acid and tetronic acid had an insignificant or no effect on the barnyard grass.

\section{Effect on the pupation and emergence of the housefiy}

(a) Fifty instar larvae of Musca domestica on the second day after hatching were placed in a beaker containing $25 \mathrm{~g}$ of artificial diets (powdered yeast-brans= $1: 1), 25 \mathrm{ml}$ of water and $25 \mathrm{mg}$ of the test compound, and reared at $25^{\circ} \mathrm{C}$. When the pupation was finished, the pupae were counted. The appearing pupae were kept in a beaker covered with a piece of guaze at $25^{\circ} \mathrm{C}$ and the emerged adults were counted. The results of

Table III. Effects on the Pupation and THE EMERGENCE OF THE HOUSEFLY

\begin{tabular}{rccc}
\hline No. & \multicolumn{2}{c}{ (a) Molting rate $(\%)$} & $\begin{array}{c}\text { (b) Insecticidal } \\
\text { activity }(\%)\end{array}$ \\
\cline { 2 - 4 } & Pupation & Emergence & \\
\hline 1 & 76 & 110 & 10 \\
2 & 89 & 87 & 30 \\
3 & & & 0 \\
4 & 82 & 73 & 0 \\
5 & & & 20 \\
\hline 6 & 96 & 84 & 10 \\
7 & 82 & 87 & 10 \\
8 & 84 & 98 & 0 \\
9 & 93 & 92 & 0 \\
10 & 107 & 80 & 0 \\
11 & 100 & 111 & 0 \\
\hline 13 & 78 & 88 & 0 \\
14 & 89 & 90 & 0 \\
15 & 58 & 76 & 0 \\
16 & & & 0 \\
17 & 107 & 80 & 0 \\
18 & 100 & 110 & 10 \\
\hline 21 & 60 & 95 & 20 \\
\hline
\end{tabular}




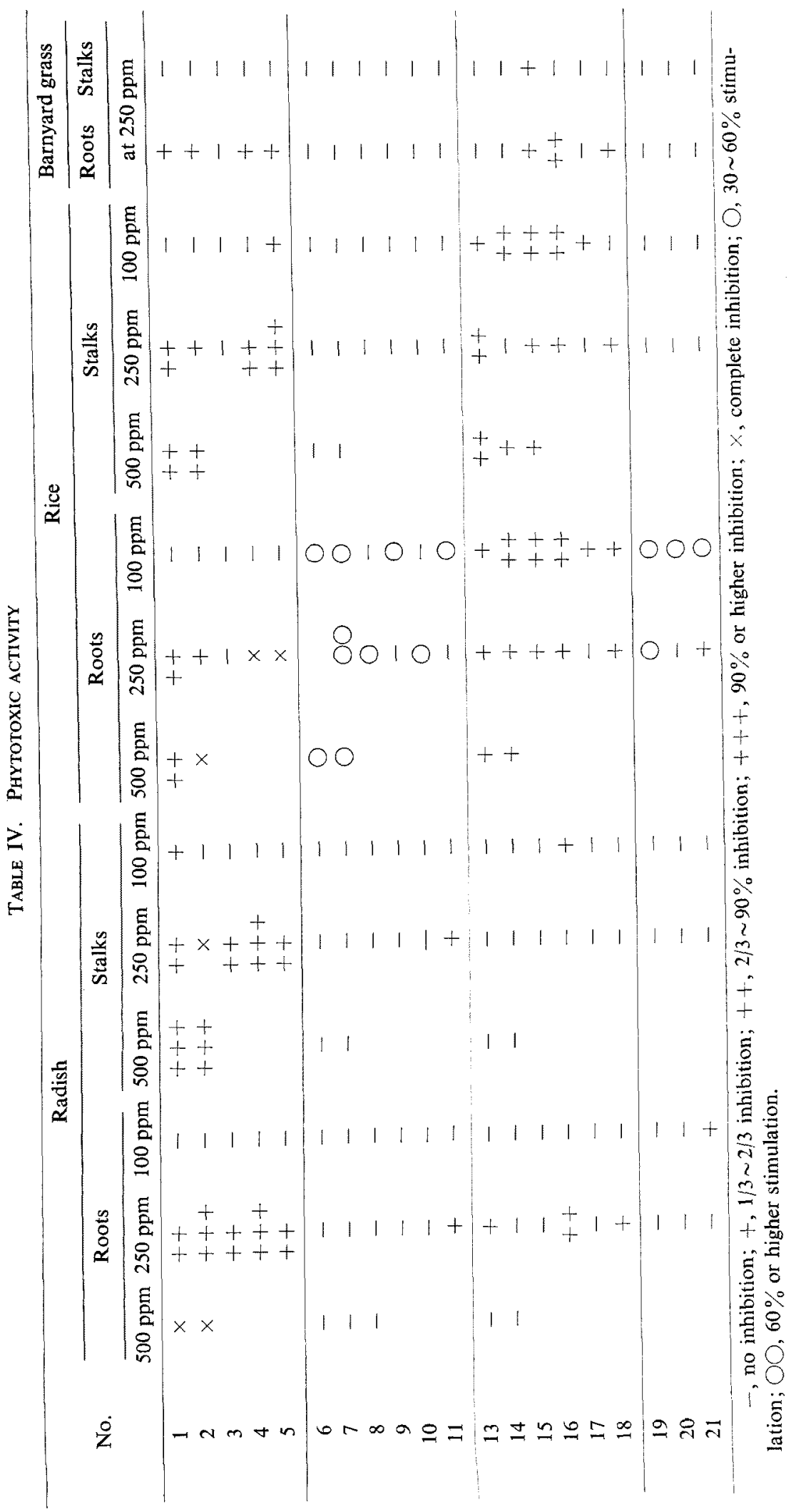


the pupation are shown as percentage against the control at the final stage of the experiment. Similarly, those of the emergence are shown as percentage. The results obtained are shown in Table III.

As seen in Table IIIa, the pupation was inhibited by some derivatives of 5 -aryltetronic acid $(13,15)$ and the benzylidene compound (21). The mortal effect was not observed in general, but compounds (4) and (8) showed it somewhat.

(b) The adult houseflies on the fourth day after emergence were placed in a beaker containing $2 \mathrm{mg}$ of the test compound, $98 \mathrm{mg}$ of sugar and absorbent cotton moistened with water, and reared at $25^{\circ} \mathrm{C}$. After 12 and $24 \mathrm{hr}$ the number of dead flies was counted. The results are shown in Table IIIb.

As shown in Table IIIb, the derivatives of tetronic acid did not show any insecticidal activity. On the other hand, some derivatives of tetramic acid $(\mathbf{2}, \mathbf{5})$ did have a slight effect.

\section{Fungicidal activity}

The fungicidal activity test on Aspergillus niger was carried out as follows. $0.5 \mathrm{mg}$ of each chemical was dissolved in a small amount of acetone and the solution was spotted onto a filter paper of $6 \mathrm{~mm}$ diameter. After spontaneous evaporation of the solvent at room temperature, the paper was put on the surface of the agar medium in a Petri-dish. Five samples and one control were placed in each Petri-dish, and then these were sprayed with spores of Aspergillus niger suspended in sterile water. After incubation for $24 \mathrm{hr}$ at $35^{\circ} \mathrm{C}$, diameters of the inhibitory zones were measured.

On the whole, the derivatives of tetramic acid and tetronic acid showed insignificant fungicidal activity against Aspergillus niger if any at all.

\section{REFERENCES}

1) Y. Mikami, Y. Nishijima and S. Tamura, Agric. Biol. Chem., 35, 611 (1971).

2) S. Iwasaki, H. Muro, S. Nozoe and S. Okuda, Tetrahedron Lett., 1972, 13.

3) C. O. Gitterman, J. Med. Chem., 8, 483 (1965).

4) S. A. Harris, L. V. Fisher and K. Folkers, J. Med. Chem., 8, 478 (1965).

5) F. M. Dean, "Naturally Occurring Oxygen Ring Compounds," Butterworth Co. 1963, p. 53.

6) R. N. Lacey, J. Chem. Soc., 1954, 850.

7) R. P. Patel, and S. Price, J. Org. Chem., 30, 3575 (1965).

8) K. Fukui and M. Nakayama, Bull. Chem. Soc. Jpn., 35, 1321 (1962).

9) K. Fukui and M. Nakayama, Nihon Kagaku Zasshi, 84, 606 (1963).

10) T. Shishido and J. Fukami, Botyu Kagaku, 28, 74 (1960).

11) R. Anschütz and R. Böcker, Ann., 368, 53 (1909).

12) G. S. Fonken and W. S. Johnson, J. Am. Chem. Soc., 74, 831 (1952).

13) E. A. S. La Croix, S. E. Mhasalkar, P. Mamalis and F. P. Harrington, Pestic. Sci., 6, 491 (1975).

14) H. Yuki, T. Tsujimoto, T. Sawada, K. Takiura and T. Yamaguchi, Yakugaku Zasshi, 96, 536 (1976).

15) T. Yamaguchi, K. Saito, T. Tsujimoto and H. Yuki, J. Heterocyclic Chem., 13, 533 (1976). 